\title{
The Incompleteness of Luck Egalitarianism
}

\author{
Ryan Long
}

Luck egalitarianism makes a fundamental distinction between inequalities for which agents are responsible and inequalities stemming entirely from luck. The aim of the view is, other things being equal, to ignore the former and rectify the latter. The ideal situation is that each person exerts an equal amount of control over her place in the distribution, and that deviations from distributive equality caused solely by luck are minimized. The essential thought behind luck egalitarianism is agnostic on the metric of equality. You can have a luck egalitarian theory about welfare, or resources, or several other metrics. We need only keep in view that these theories aim to make distribution (of whatever metric) shaped primarily by things for which the agent is responsible, such as informed and free choices, and to compensate for inequalities stemming solely from luck. Paradigm forms of luck that generate unjust inequalities are the wealth or class of the family to which one is born, discrimination based on one's sex or race, and the market value of one's native endowments (the portion of one's talents that are purely innate rather than intentionally cultivated). The view is compatible with great levels of distributive inequality, so long as those inequalities have the proper sorts of causes. When a bearer of an inequality is responsible for her condition, that inequality can be just. 
The egalitarian theories of G.A. Cohen, Ronald Dworkin, Larry Temkin, John Roemer, and Richard Arneson are prime examples of luck egalitarian views. Arneson claims this group is united in thinking that "the essence of social justice is the imperative to improve the condition of people who suffer from simple bad luck."1 ${ }^{1}$ Temkin argues that "it is bad---unjust and unfair---for some to be worse off than others through no fault [or choice] of their own." ${ }^{2}$ Dworkin argues for a view that is "ambition sensitive" and "endowment insensitive", in other words, sensitive to choices and efforts, insensitive to arbitrary circumstances and native endowments. Cohen claims that "genuine choice excuses otherwise unacceptable inequalities." ${ }^{3}$ These theorists all view deviations from distributive equality through the lens of responsibility. Whether it is unjust for someone to be worse off than others depends on whether that person is responsible for being worse off than others. Whether it is unjust for someone to be better off than others depends on whether they have done anything to deserve being better off, or whether they are merely lucky (e.g., born into a privileged position). Inequalities stemming from choice are treated differently from inequalities stemming from luck.

The only conditions under which these theories allow luck to generate just inequalities are when we make free choices whose outcomes are shaped by luck. This is what Dworkin calls option luck, as opposed to the mere brute luck of, say, your starting place in society or your innate talents. If a person makes a free choice to take a risk, under ideal conditions they can be responsible for that choice. A resulting inequality can 
therefore be just, even though it is partially generated by forces outside that person's control. Therefore luck egalitarianism does not attempt to neutralize all luck. It rather wants to make the distribution of benefits and burdens in society maximally sensitive to choice, even if those choices have outcomes that are partially determined by forces outside the agent's control. Luck egalitarianism primarily wants to neutralize inequalities that stem from brute luck.

In this paper I will motivate luck egalitarianism as a compelling theory, argue that it is incomplete and lacks the normative resources to achieve its stated ends, and then briefly outline my strategy for rehabilitating the theory. My primary goal is to develop a new criticism of luck egalitarianism, and to argue that the same concerns that push one to accept the view also lead one to conclude that it is an incomplete view of equality. The positive remarks at the end attempt to briefly outline a strategy for solving this problem without rejecting luck egalitarianism entirely.

\section{Motivating Luck Egalitarianism}

\subsection{The Value of Choice}

There is a prima facie plausibility to a morally and politically salient distinction between choice and luck. The distinction shapes ethical judgment. We evaluate what an agent chose or did, not what happened to or befell the agent. That which is outside the domain of choice seems outside the domain of responsibility. In the context of egalitarianism, this distinction indicates that our lives should be sensitive to our choices--- 
distributive justice should not make lives insensitive to choice, or do away with the option of taking substantive risks. Choice sensitivity is of intrinsic and instrumental value.

The intrinsic value is illuminated when we consider that the alternative, undermining choice-sensitivity, is incompatible with our conception of ourselves as free and autonomous agents. Consider what Scanlon calls the symbolic value of choice---if we are free to choose then we are seen and treated as someone qualified to choose. If we are not allowed to make a choice, this is demeaning. ${ }^{4}$ Typically we abridge the power of choice for children or those who are deemed deficient in some way, or we abridge the power of choice based on a patriarchal rationale. The egalitarian upshot is that our lives should not be unduly shaped by that which is not the product of our choices. Our welfare, resources, social status, and opportunities should not fundamentally be determined by forces outside our control.

The instrumental value of choice-sensitivity has to do with theories of productivity and efficiency. For familiar laissez faire reasons, it is thought that conditions of unconstrained choice lead to greater productivity. Under such conditions we will have a larger amount of goods to distribute than if choices were regulated and constrained, and thus we will be in a stronger position to aid those who are worse off than others through no fault of their own. Choice sensitivity also encourages efficiency in the following way. If agents know that they must bear the benefits and burdens of their choices, this incentivizes prudent choices. 
We see then that this value of choice is ecumenical. It can be supported by leftist concerns for autonomy, rightist concerns for negative liberty, or economic concerns about efficiency and productivity. All of these favor choice-sensitivity, and insofar as luck egalitarianism emphasizes choice-sensitivity, it is justified by the value of choice. Luck egalitarianism gives us a way to pursue a form of equality without letting the imprudent exploit the prudent, and without subsidizing bad choices. It follows that luck egalitarianism can be endorsed by those who otherwise would not be egalitarians. As Cohen says, luck egalitarianism can co-opt "the most powerful idea in the arsenal of the anti-egalitarian right: the idea of choice and responsibility." 5 The things anti-egalitarians typically find objectionable about a commitment to equality, such as an impulse to have strict distributive equality for its own sake (which strikes them as based in envy), or the possibility that we ought to level down everyone's condition in order to reach equality, or that we need to subsidize bad choices, are not in view here.

\subsection{Resolving Troublesome Distributive Cases}

If our metric of equality has anything to do with welfare, that is, with the happiness or pleasure one gets out of life, then we have the problem of expensive tastes. To obtain the same level of welfare, people with different tastes may require radically different amounts of resources. But it hardly seems fair to redistribute more resources to someone simply because they have expensive tastes. What if I need champagne to obtain a given level of welfare, but you can obtain it with the champagne of beers? Is it fair to subsidize 
my expensive taste? Even more worrisome, suppose that I have knowledge of the egalitarian scheme that is operative and then intentionally exploit the system by developing expensive tastes just to procure more resources.

Egalitarian theories that do not fundamentally appeal to the luck/choice distinction either have to move away from any concern for welfare, or they must subsidize too many cases of expensive tastes. Neither of these alternatives is very attractive. On the other hand, luck egalitarianism can make a distinction between tastes for which the person is responsible, and tastes for which they are not. If we make a distinction between tastes that are chosen or intentionally cultivated versus tastes that are the product of environment, or are not identified with, or that the agent chooses to struggle against or revise, then we can get the right outcome in these cases. Only tastes that are strictly beyond the control of the agent, and hence cannot be considered the agent's responsibility, pose a problem of justice. Of course taking one of these strategies requires a lot of hard work in terms of spelling out how tastes are acquired and what sort of control we can exert over tastes. But luck egalitarianism has the resources to allow such work to be done, and in terms of fairness that is a substantial improvement over alternate responses to expensive tastes. When we understand equality in terms of choice and responsibility, we are only concerned with expensive tastes in cases where their bearer absolutely cannot help having them and cannot change them. 
Luck egalitarianism can give a similar response to the problem of free riders, those who would reap the benefits of a redistributive scheme without doing their fair share. We can differentiate those who cannot work and are not responsible for that fact from those who choose not to work, and we can subsidize only the former. This is another way that luck egalitarianism co-opts the values of anti-egalitarians and can attract adherents from across the political spectrum.

Another puzzling case has to do with how we prioritize aid under conditions of scarcity. If we can only aid a subset of candidates, it coheres with our understanding of fairness to first address those least responsible for their predicament, and then last (if at all) those who made choices that caused their predicament. Consider an example that Arneson uses to present the "basic idea" of luck egalitarianism. Suppose three groups of hikers are stranded on a mountain in a blizzard: experienced climbers who took a calculated risk and entered dangerous terrain marked with warning signs, children on a tour who are trapped in unmarked and typically safe terrain, and reckless tourists who ignored the warning signs and entered dangerous terrain. ${ }^{6}$

Further suppose we can only rescue one group. We are to pick which group based on the intrinsic merit of the decision---not based on what instrumental value the choice has in shaping future behavior. (Suppose the park is closing permanently.) It seems our intuition is that the children are most deserving of being saved. The climbers chose to take an informed risk and under the circumstances it is not unfair to make them bear the 
cost of that risk. The tourists were negligent, so again, it is not unfair to make them bear the consequences of their negligence. They violated a normative standard when they chose to ignore a warning that they ought to have heeded. The children are clearly the least responsible for their predicament. Arneson argues that the basic idea of luck egalitarianism is that the children deserve saving because their predicament is not due to choice. $^{7}$

This is the procedure luck egalitarianism uses to resolve cases in which, due to some scarcity, we cannot aid all candidates. We rank situations by the extent to which they were generated by choice, which is to say, the extent to which the relevant agents are responsible for their predicaments. We prioritize aid to those least responsible for their predicament, and only then, if at all, give aid to those who are responsible. This gives a fair outcome in terms of expensive tastes, free riders, and aiding people under conditions of scarcity. Arneson's rescue example is artificial, but the reasoning can apply to many forms of scarcity. It can be used to argue that we ought to prioritize liver transplants in light of individual behavior, so that we aid last those who can be held responsible for damaging their livers through drinking. (I do not intend to defend such a policy here, but merely present it as an example of how this basic idea can be applied to a wide range of problems.)

This should be sufficient to show why one might be attracted to the basic idea of luck egalitarianism. I now turn to my criticism. I argue that any tenable form of luck 
egalitarianism, that is, any theory that puts defeasibility conditions on when individual choices have the right character to generate just inequalities, must not define equality solely in terms of choice, luck, and responsibility. Luck egalitarians are forced to become pluralists, because their theory is inadequate to achieve their stated ends. They must incorporate other egalitarian values.

\section{The Incompleteness of Luck Egalitarianism}

Luck egalitarianism is not a full theory of equality. The theory's aim is to specify the justice (or injustice) of particular deviations from distributive equality in terms of the distinction between choice and luck. If the bearer of an inequality is genuinely responsible for her condition, then (absent other considerations) that inequality is not unjust. However, the resources internal to luck egalitarianism are inadequate to complete this project.

A given luck egalitarian theory is tenable only if it puts some defeasibility conditions on how individual choices can generate just inequalities. Tracing a given inequality back to an act of will does not alone show that it is just---what if the agent was coerced or had a severely constrained set of choices? What if the agent was privileged and had the option to take many favorable gambles unavailable to others?

In response to this problem Dworkin makes a compelling and natural, but flawed,

move. He claims that "the argument in favor of allowing differences in option luck to affect income and wealth assumes that everyone has in principle the same gambles 
available to him. Someone who never had the opportunity to run a similar risk, and would have taken the opportunity had it been available, will still envy some of those who did have it." ${ }^{8}$ My objection is that this gives us a picture of just inequalities that either sets an unattainable standard, or is indeterminate.

One the one hand, we could have a resolute reading of the requirement that everyone have the same set of available gambles. However, actual gambles are in fact (almost) never in principle available to everyone, in which case Dworkin's theory judges few (or no) inequalities to be just. Thus the strong initial commitment to the value of choice would undermine itself, since it turns out that no choices actually meet the standard required for a resulting inequality to be just. This is unacceptable, since the theory was supposed to explain the difference between just and unjust inequalities, but it turns out that nothing meets the standard of being a just inequality.

On the other hand, we could specify the meaning of "in principle" sameness in a weaker sense. However, this cannot be done merely in the luck-egalitarian language of choice alone. In the first prong of the dilemma, his theory undermines itself, given its strong initial commitment to choice and responsibility. The second prong shows his theory is incomplete, and that if we want to remain luck egalitarians, we must move toward a pluralist understanding of equality. I present the argument against Dworkin, but this is a general problem facing any luck egalitarian theory that wants to employ defeasibility conditions. 
In order to gloss what "in principle" sameness means, we have to find a standard on a continuum from fine-grained to coarse-grained. At the fine-grained extreme, having the same opportunities to take gambles would mean having the exact same gambles. At the coarse-grained extreme we would specify gambles in a maximally abstract sense--perhaps 'to take a gamble on owning a business'. It is not entirely clear where this end would terminate, but the idea is clear enough for our purposes. At the fine-grained extreme you and I must have options to take the exact same gambles. At the coarsegrained extreme these gambles become abstract and fungible, so that two persons can have the same options in principle, even though they are not strictly equivalent options.

The fine-grained extreme is clearly not Dworkin's view, nor is it a tenable view. It is simply the resolute reading given above. Dworkin's use of the phrase "in principle," is a way to move away from the fine-grained extreme. If he endorsed the resolute reading, Dworkin would have said all persons must have available the exact same gambles, not "in principle" the same gambles. In any case, the fine-grained extreme is not a tenable view because even the most invasive totalitarianism could never achieve exact parity of opportunities among a substantial set of citizens. Even in a highly egalitarian state, the options available to a given person will vary according to numerous factors, including their family and upbringing. We could never meet the condition that all people have the same options to take the same gambles. On this reading, the theory sets choice-based conditions on just inequalities that could never be met. 
Thus we need to move on the continuum away from that extreme. To determine where we stop on the continuum, we must appeal to some further value or concern outside of luck egalitarianism. To say that two sets of available gambles are in principle the same is to say they are equivalent by some standard outside that continuum, to say that they are non-identical yet equal enough. There is nothing intrinsic to the concepts of choice, responsibility, or luck that will determine where we should be on this continuum. Those concepts are insufficient to tell us whether sets of options A and B are in principle the same. We need some further egalitarian value to tell us when two sets of options are in principle the same, because this is precisely a question about equality itself---what is it for two agents to be situated in circumstances that are not exactly the same, but equivalent enough such that the choices that they make can matter to distributive justice?

In order to determine whether two sets of gambles are equal enough, we need some normative standard. But luck egalitarianism's only norm is the value of choice, and that value is of no use here. Luck egalitarianism starts with a normative claim that individual choices have some value, and that our distribution should be highly choicesensitive. Beyond that, luck egalitarianism is primarily a theory of causal origins; to evaluate a given inequality, we look at what caused it. This is of no help whatsoever in determining whether two sets of options are in principle the same. We need something beyond the value of choice to answer that question. 
Therefore luck egalitarianism is incomplete. I make this point against Dworkin, but it is utterly general. If you want instead a defeasibility condition that states everyone simply needs some minimal set of opportunities, then you have the same problem. Luck egalitarianism cannot determine a just and sufficient minimum floor. It does not have the normative resources.

\section{A Brief Sketch of a Solution}

I see two possible strategies for reforming luck egalitarianism. One is to incorporate further egalitarian values to help determine when two sets of options are equivalent enough. The other is to incorporate further egalitarian values to determine when persons have a sufficient set of available options. If we can successfully pursue either strategy then we will have the normative resources to resolve the defeasibility problem, and thus luck egalitarianism will be able to set clear, attainable conditions on when individual choices generate just deviations from distributive equality.

The most promising strategy is to define a sufficient set of options. I suspect that any attempt to determine a workable standard for specifying when two sets of options are equivalent enough will have to be so coarse-grained that it essentially collapses into the strategy of defining a sufficient set of options. The mere presence of the traditional family is sufficient to ensure that there will be substantial differences in the opportunities that different citizens have. Citizens will always have qualitatively different options available to them. Some citizens will also simply have more options than others, so there is no way 
to put the options available to different citizens in one-to-one correspondence. These are facts we simply must accept, since even totalitarian intervention cannot change them. I am also extremely skeptical that we ought to be concerned with everyone having an equivalent set of opportunities, because this is close to valuing strict equality for its own sake and thus again raises the specter of envy. In some cases, it simply does not matter whether two persons had the same opportunities. Consider two extremely privileged individuals, one slightly more privileged than the other. If the slightly more privileged individual takes a risk unavailable to the slightly less privileged individual, and this leads to greater inequality between them, that does not concern me. Both of them had a wide range of opportunities and a fair chance to flourish in their society.

My preferred method for resolving this problem is a transition from Dworkin's concern over the equality of sets of available gambles to a concern over the social equality of persons. By social equality I have in mind something similar to Elizabeth Anderson's conception of democratic equality. ${ }^{9}$ (This means I am co-opting one of the most powerful ideas in the arsenal of the anti-luck-egalitarian left.) A conception of social equality could appeal to what one needs to fully function as a citizen in a particular society, and what one needs to stand in social relationships to other citizens that are characterized by equal respect. If social equality requires that everyone has some minimal set of available options and some minimal amount of resources, then the question will not be whether everyone has in principle the same set of available gambles, but whether everyone has a 
sufficient set. This makes the defeasibility problem tractable. Going back to the language of "fine grained" and "coarse grained," we will give a relatively coarse-grained description of what sorts of options must be available to everyone to guarantee social equality.

Once we articulate a particular conception of the citizen and what is required for citizens to stand in social relations of equality, we can generate a benchmark for judging a set of available gambles sufficient. If a citizen chooses from among a sufficient set of available gambles, then her choices can create just deviations from strict distributive equality. We can go on to define types of gambles in terms of various goods and ends that are crucial to social equality. These key domains of choice would include opportunities for employment, income, education, mobility, recreation, self-expression, self-respect, and so on. As long as everyone has what they need to fully function as a citizen (such as access to education, the ability to move throughout the public sphere, a minimum level of material well being and security, access to information so they can be an informed voter, etc.), and as long as everyone has some sufficient set of opportunities available in each key domain of choice, then we have a genuine equality of position among persons. Luck egalitarianism needs this prior form of equality to obtain in order for the value of choice to carry any weight. Only when those conditions obtain can individual choices generate just deviations from strict distributive equality. When these conditions do not obtain, citizens are making their choices from radically unequal starting positions, and thus there is no 
reason to think individual choice can generate just deviations from distributive equality. This minimum sufficient standard of material well being and available opportunities should be understood as society-specific, and as something that will change over time. It is a political question that must be worked out in light of the opportunities a given society makes available, that society's productive capacity, its resources, and so on.

This is how to resolve the incompleteness of luck egalitarianism. My argument establishing the incompleteness of the view was completely internal, that is, it did not involve objections based in any competing view of equality. My solution to the problem, the appeal to a minimum set of opportunities and resources that each citizen must have to fully function as an equal citizen, also lets us solve many of the strongest external criticisms of luck egalitarianism. I will give one example. Elizabeth Anderson argues that luck egalitarianism abandons those citizens whose choices lead to catastrophic outcomes, and that the theory expresses no concern for the well-being of such persons. She discusses several cases of the following sort. Suppose a driver chose to forego all forms of insurance, and then negligently makes an illegal turn that causes an accident. This negligent driver suffers terrible injuries. He now requires extensive medical care and will require ongoing aid to deal with his permanent disabilities. Anderson worries that luck egalitarianism leads us to abandon this person entirely, because this person is responsible for their predicament and the theory sets no minimum floor of well-being and material security. ${ }^{10}$ The problem can be generalized beyond this to include individuals whose 
choices lead to crushing poverty, either because they made imprudent choices or because they made prudent choices but nonetheless suffered terrible option luck in the marketplace.

My resolution of the internal incompleteness problem also solves this external objection. My variant of luck egalitarianism requires that everyone has a sufficient set of opportunities. For those opportunities to be meaningful, and for each person to be able to fully function as a citizen, there must be a minimum level of material well-being guaranteed for all. That minimum level is not forsaken even when individuals make choices that would otherwise put them in a desperate situation. Choice-sensitivity no longer requires us to abandon anyone. Everyone needs a minimum set of opportunities and a minimum level of material well-being for luck egalitarianism to be a compelling theory. When this condition does not obtain, then we ought not think that individual choices can generate just deviations from equality, because many choices will simply perpetuate prior unjust inequalities. Luck egalitarianism's emphasis on choice only makes sense when everyone is making their choices from a position of relative material security, and when they are choosing among a sufficient menu of real options. Further development of this strategy will allow us to preserve the deep truth in luck egalitarianism while resolving its incompleteness and improving its response to those people whose choices threaten their basic ability function as citizens. 


\footnotetext{
${ }^{1}$ Richard J. Arneson, "Luck Egalitarianism Interpreted and Defended". Currently available on his website (philosophyfaculty.ucsd.edu/faculty/rarneson/luckegalitarianism2.pdf) and forthcoming in Responsibility and Distributive Justice, ed. Carl Knight and Zofia Stemplowska, Oxford University Press

${ }^{2}$ Larry Temkin, Inequality, Oxford University Press, (1993), p.13 fn. 21

${ }^{3}$ G.A. Cohen, "On The Currency of Egalitarian Justice," Ethics, 99, (1989), p. 931

4 T.M. Scanlon, What We Owe To Each Other, The Belknap Press, (1998).

${ }^{5}$ Cohen, ibid, p.933

${ }^{6}$ Richard J. Arneson, “Luck Egalitarianism and Prioritarianism", Ethics, 110 Jan. (2000):2, p.4

${ }^{7}$ Note that any attempt to explain away this case due to special obligations to children will not refute Arneson's conclusions. The example works as well if all parties are adults. Arneson's use of children in this example unfortunately clouds the issue.

8 Ronald Dworkin, "What is Equality? Part 2: Equality of Resources", Philosophy and Public Affairs, 10 Autumn (1981):4, p.296

${ }^{9}$ Elizabeth Anderson, “What is the Point of Equality?" Ethics, 109 January (1999):2, p.313

${ }^{10}$ Anderson, ibid, p.295
} 